\title{
ORDENAMENTO TERRITORIAL NO BRASIL: UMA ANÁLISE CONTEXTUALIZADA A PARTIR DAS DIVISÕES REGIONAIS IMPLEMENTADAS PELO IBGE
}

\author{
Lívia Jordana Assis Pereira ${ }^{1}$, Larissa da Silva Ferreira Alves ${ }^{2}$ \\ ${ }^{1}$ Mestra em Planejamento e Dinâmicas Territoriais no Semiárido (PLANDITES) pela \\ Universidade do Estado do Rio Grande do Norte (UERN) - Campus Avançado de Pau dos \\ Ferros (CAPF), Pau dos Ferros - RN. liviajjordana@hotmail.com \\ ${ }^{2}$ Professora adjunta do Departamento de Geografia e docente permanente do Programa \\ de Pós-graduação em Planejamento e Dinâmicas Territoriais no Semiárido (PLANDITES) \\ da Universidade do Estado do Rio Grande do Norte (UERN) - Campus Avançado de Pau \\ dos Ferros (CAPF), Pau dos Ferros - RN. larissaferreira@uern.br
}

\section{Recebido em: 15/11/2021 - Aprovado em: 15/12/2021 - Publicado em: 30/12/2021 DOI: 10.18677/EnciBio_2021D34}

trabalho licenciado sob licença Creative Commons Attribution-NonCommercial-NoDerivatives 4.0 International License.

\begin{abstract}
RESUMO
As discussões inerentes ao ordenamento territorial são vistas nos últimos anos como tema em relevo. Comumente usada como ferramenta destinada ao aporte de políticas públicas de gestão, essa temática constitui o pano de fundo para diversas pesquisas. A compreensão dos processos de formação, planejamento e organização de um território implica, via de regra, numa análise sistematizada de seus aspectos sociais, políticos e econômicos. No caso do Brasil, dada a sua significativa heterogeneidade, o entendimento da problemática em tela torna-se um tanto mais complexo, o que remete a um propositivo estudo das especificidades referentes ao seu processo de ordenamento territorial. Mediante essa premissa, o presente artigo teve como objetivo analisar a evolução do processo de ordenamento do território brasileiro com base nas propostas de regionalização implementadas pelo IBGE ao longo dos séculos XX e XXI. Para tanto, adotou-se como método uma revisão bibliográfica baseada na interlocução de postulados teóricos clássicos, bem como, em diversos estudos e pesquisas que alicerçam o tema em análise. Como resultado, chega-se a um constructo teórico sobre o ordenamento territorial do Brasil à luz dos seus processos de regionalização.
\end{abstract}

PALAVRAS-CHAVE: Brasil; Divisão regional; IBGE; Ordenamento territorial.

\section{TERRITORIAL PLANING IN BRAZIL: A CONTEXTUALIZED ANALYSIS FROM THE REGIONAL DIVISIONS IMPLEMENTED BY IBGE}

\begin{abstract}
Discussions inherent to territorial planning have been seen in recent years as a prominent theme. Commonly used as a tool for the contribution of public management policies, this theme constitutes the background for several researches. Understanding the process of formation, planning and organization of a territory usually implies a systematized analysis of its social, political and economic aspects. In the case of Brazil, given its significant heterogeneity, the understanding of the problem at hand becomes somewhat more complex, which leads us to a purposeful study of the specifics regarding its territorial planning process. Based on this premise, this article aims to analyze the evolution of the planning process of the Brazilian territory based on regionalization proposals implemented by the IBGE throughout the
\end{abstract}


20th and 21st centuries. Therefore, a literature review was adopted as a method based on the interlocution of classical theoretical postulates, as well as on several studies and research that support the topic under analysis. As a result, a theoretical construct is reached on the territorial ordering of Brazil in the light of its regionalization processes.

KEYWORDS: Brazil; Regional division; IBGE; Land use planning.

\section{INTRODUÇÃO}

O processo de planejamento, regionalização e organização de um território não é tarefa fácil, sobretudo, quando este é marcado por uma significativa heterogeneidade, como é o caso do Brasil. Conforme abaliza a literatura consultada, os territórios não são estáticos. Estes se apresentam em contínua transformação. Santos e Silveira (2014, p.20) apontam que "o território, visto como unidade e diversidade, é uma questão central da história humana e de cada país e constitui o pano de fundo do estudo das suas diversas etapas e do momento atual".

$\mathrm{Na}$ análise e/ou definição de qualquer pedaço de território, deve-se levar em consideração "a interdependência e a inseparabilidade entre a materialidade, que inclui a natureza, e o seu uso, que inclui a ação humana, isto é, o trabalho e a política" (SANTOS; SILVEIRA, 2014, p.247). Partindo desse pressuposto, compreende-se que a regionalização e ordenamento de um território estão intrinsecamente relacionadas aos diversos agentes e fatores que (re)produzem e consomem esse espaço.

No tocante ao Brasil, a formação de seu território é marcada por um longo e complexo processo de ordem política, econômica e social. As delimitações fronteiriças do vasto território ocorreram num período de aproximadamente quatro séculos (do século XVI ao século XIX). Entretanto, durante esse período percebeuse uma espécie de inércia no que diz respeito à organização territorial, conforme Andrade (2004, p.20):

[...] o Brasil, que possui desde o período colonial um grande espaço, durante séculos não o transformou, por meio do exercício de sua gestão, só vindo a tentar fazê-lo a partir dos meados do século XX, quando o Governo Vargas, no Estado Novo, criou a Fundação Brasil Central e pregou 'a marcha para o Oeste', procurando expandir a área de ação e de domínio do Governo [...] (ANDRADE, 2004).

De acordo com Carvalho et al. (2019, p.239), "No Brasil [...], o enfoque das políticas públicas para o ordenamento territorial se deu a partir de um período muito recente da história do País, diferentemente do que aconteceu com países desenvolvidos, onde essa preocupação aconteceu há mais tempo [...]".

Assim, a análise dos processos de planejamento e ordenamento do Brasil direciona, impreterivelmente, a uma leitura sistematizada de postulados teóricos, cujas bases analíticas estão imersas nos vieses históricos, políticos e socioeconômicos que fundamentam a composição do território brasileiro. Conforme abaliza Haesbaert (2020), "o passado e o presente, é claro, não são excludentes, sendo necessário um tratamento histórico consistente para atender as atuais transformações em curso no nosso País".

Isto posto, a problemática e objetivo desta pesquisa estão voltados ao entendimento do ordenamento territorial do Brasil, correlacionando-o aos modelos de regionalização implementados pelo IBGE ao longo dos séculos $X X$ e XXI. Para tanto, adotou-se como método uma revisão bibliográfica, alicerçada na interlocução 
de referências clássicas e/ou estudos e pesquisas referentes aos principais postulados teóricos que tratam da temática em discussão.

\section{TERRITÓRIO, ORDENAMENTO TERRITORIAL E GOVERNANÇA: BREVES CONSIDERAÇÕES}

As discussões inerentes ao conceito de território constituem objeto de análise de diversas produções científicas. Conforme destaca Oliveira (2020, p.43), trata-se de um conceito multidimensional, no qual fazem parte as dimensões material, social, política, econômica, antropológica, entre outras. Para Santos e Silveira (2014, p.19), "por território entende-se geralmente a extensão apropriada e usada". Conforme os referidos autores:

[...] defrontamo-nos com o território vivo, vivendo. Nele, devemos considerar os fixos, isto é, o que é imóvel, e os fluxos, isto é, o que é móvel. Os fixos são, geralmente, constituintes da ordem pública ou social, enquanto os fluxos são formados por elementos públicos e privados, em proporções que variam segundo os países, na medida em que estes são mais ou menos abertos às teses privatistas (SANTOS;SILVEIRA, 2014. p.247).

Nessa perspectiva, compreende-se que o uso do território pode ser definido desde a implementação de infraestruturas até as ações oriundas do dinamismo da economia e da sociedade. Nos últimos anos, esse dinamismo ocorre mais intensamente pelo uso da ciência e da técnica (SANTOS;SILVEIRA, 2014, p.21).

De forma complementar, Moreira (2019, p.90-91) define o território como "recorte espacial a partir do qual os sujeitos/categorias dos fenômenos se posicionam diante dos termos da hegemonia ou coabitação determinados pela dialética da localização-distribuição". Ainda, conforme o autor, "o território é sempre uma dimensão do espaço político (ou ao espaço tomado como ação política)".

Sposito e Saquet (2016, p. 18), apontam que "o território se complementa [...] com o conceito de territorialidade que qualifica o papel dos agentes que atuam na conformação dos territórios e das microterritorialidades". A territorialidade, ou seja, o sentimento de pertencimento a algum lugar ou a algo acaba remetendo a uma lógica de apropriação que reflete na indução dos modos de organização e regulação do território. É, portanto, nesse contexto, que encontra-se terreno fértil para contextualizar o ordenamento territorial.

De acordo com Pujadas e Font (1998), o ordenamento territorial pode ser classificado através de três perspectivas: como disciplina científica, como técnica administrativa e, por fim, como política pública. Ainda conforme os autores, uma das definições mais aceitas sobre o ordenamento territorial a descreve como "la expressión espacial de las políticas económicas, sociales, culturales y ecológicas de la sociedad [...]" (PUJADAS;FONT, 1998, p.11).

Do exposto, conjectura-se que o ordenamento de um território deve estar pautado fundamentalmente no planejamento e execução de um conjunto de ações organizadas, estrategicamente, em um plano, cuja finalidade alinha-se, entre outros fatores, ao processo de desenvolvimento de um país (PUJADAS;FONT, 1998).

Baseado na perspectiva de análise do território sob 0 enfoque do ordenamento observa-se com primazia, a relevância da governança nesse processo. De acordo com Dasí (2008, p.12), o conceito de governança territorial tem origem no âmbito da economia institucional e de regulamento, tendo como objetivo principal simplificar os processos de regulamento e intervenção dos poderes públicos, além de facilitar as tomadas de decisão dos agentes sociais sobre os econômicos. Ainda 
para o autor, "La gobernanza territorial se ha convertido en el instrumento em el que se encuentran depositadas las esperanzas de una más efectiva gestión y gobierno de las políticas de desarrollo territorial" (DASí, 2008, p.11).

Grosso modo e, em conformidade com os postulados teóricos sobre os temas em tela, é possível compreender que, dentro do contexto do ordenamento territorial, a governança apresenta-se como um modelo mais simplificado de gerir os assuntos públicos relacionados ao âmbito do desenvolvimento territorial (DASÍ, 2008, p.12).

Mediante tais discussões, observa-se que no caso do Brasil a temática em análise apresenta-se de forma mais complexa, haja vista as peculiaridades do território nacional marcado, sobretudo, por uma expressiva heterogeneidade natural, social e econômica. Considerando as diferenciações do território brasileiro, Santos e Silveira (2014. p.259) destacam algumas situações características que auxiliam na compreensão dessa análise. São: i) zonas de densidade e de rarefação; ii) zonas de fluidez e viscosidade do território; iii) os espaços de rapidez e de lentidão; iv) os espaços luminosos e os espaços opacos, entre outros.

Das opções em destaque, um bom exemplo de análise do quadro de heterogeneidade do Brasil pode ser realizado pela ótica das zonas de densidade e de rarefação. Nestes termos, conforme os referidos autores, "[...] o exame do território permite referir, seja as densidades das coisas naturais (por exemplo florestas, vegetação, forma de relevo, etc.) e das coisas artificiais, próteses acrescentadas à natureza" (SANTOS;SILVEIRA, 2014, p.260).

Ademais, em consonância com Freitas-Firkowski (2019, p.94) é lícito reforçar que, "leituras sobre o território, em particular num país com as dimensões do Brasil, exigem constante aprimoramento metodológico e observação atenta e sistemática da realidade, tarefa que tem sido cumprida de modo competente pelo IBGE ao longo de sua existência".

De forma complementar, a autora destaca que "a produção de uma gama de informações e, em especial, de séries históricas que possibilitem a comparação no tempo e no espaço, garantem aos pesquisadores uma fonte segura e confiável de obtenção de dados e interpretações da realidade" (FREITAS-FIRKOWSKI, 2019, p.94).

Considerando essas premissas, para o entendimento da formação do território nacional e as ações de seu ordenamento, optou-se nesta pesquisa por uma análise contextualizada a partir dos modelos de divisão regional implementadas pelo IBGE durante os séculos XX e XXI. Dessa forma, ressalta-se a utilização do estudo "Divisão regional do Brasil em regiões geográficas imediatas e regiões geográficas intermediárias: 2017", como estrutura basilar desta produção, haja vista seus apontamentos sobre o percurso histórico e análises inerentes à temática em discussão.

É relevante ainda destacar que, conforme aponta Araújo (2017, p.123), "a questão da regionalização sempre esteve em pauta no pensamento geográfico brasileiro, especificidades históricas do território nacional fizeram com que diferentes ideias sobre como dividir a espacialidade continental do País surgissem ao longo dos anos".

\section{DIVISÕES REGIONAIS DO TERRITÓRIO BRASILEIRO NO SÉCULO XX}

Uma das características mais marcantes do Brasil é a grande extensão territorial. Santos e Silveira (2014, p.249), apontam que os lineamentos definitivos do mapa do Brasil foram estabelecidos durante os quatro primeiros séculos datados após o 'descobrimento', ou seja, até o século XIX. Ainda conforme os autores, o 
território nacional ampliou-se a partir da ultrapassagem da linha de Tordesilhas, através da conquista dos sertões, da presença cada vez mais ampla na bacia amazônica, da remodelação das fronteiras na bacia do Prata e da conquista do Acre (SANTOS;SILVEIRA, 2014, p.249).

É relevante ainda esclarecer que a conquista interna das terras brasileiras se deu, sobretudo, mediante as atividades econômicas vigentes em distintas porções do território nacional. Também conhecidas como ciclos da economia, essas atividades promoveram significativas mudanças no contexto socioeconômico brasileiro, bem como, (re)configurou os espaços internos do País (ANDRADE, 2003; FURTADO, 2007 [1959]; SANTOS;SILVEIRA, 2014).

Nos primórdios do século $\mathrm{XX}$, a tradicional estrutura socioeconômica brasileira, de base predominantemente rural, dava seus primeiros sinais de mudança. Mais precisamente, a partir do final de 1930, durante o Estado Novo da Era Vargas, época em que teve início a industrialização no País, percebe-se um novo e dinâmico movimento no processo de planejamento e formação político/administrativa do território brasileiro (PORTUGAL;SILVA, 2020).

Nesse período, o Governo Federal interviu diretamente em vários setores da organização do País, com o objetivo de regular e direcionar o crescimento nacional, através de políticas de ocupação e modernização do território. O projeto nacional brasileiro, pautava-se, fundamentalmente, nos aspectos de ocupação demográfica e econômica dos chamados vazios territoriais, na segurança nacional e na integração dos mercados regionais (SILVA, 2018).

Outrossim, fatores como a necessidade de unificar um território tão vasto e, em algumas regiões tão desconhecido; a ocorrência de uma modesta atividade de desconcentração espacial da produção nacional para regiões do interior do território e a criação de Territórios Federais em estados fronteiriços de grande extensão territorial e baixa densidade demográfica como Amazonas, Pará e Mato Grosso, também foram extremamente relevantes nesse processo (IBGE, 2017, p.15).

Em meio a essa conjuntura, destaca-se a criação do Instituto Brasileiro de Geografia e Estatística (IBGE). Segundo Contel (2014, p.1), a concepção do referido órgão ocorre,

[...] num contexto de radical transformação do Estado Brasileiro [...]. Os processos de burocratização e centralização do poder político se materializam na criação de Conselhos, Comissões, Institutos, Companhias, Fundações, além da promulgação de uma série de leis e de decretos que alterariam a história do país.

Formado a partir da reunião do Conselho Nacional de Estatística - CNE e do Conselho Nacional de Geografia - CNG, ambos instituídos na década de 1930, a criação do IBGE ocorre em razão de um contexto em que apresentava-se, em relevo, a necessidade do conhecimento mais detalhado sobre a sociedade e o território nacional (aspectos demográficos, produtivos, de infraestrutura, organização social e de suas bases fisiográficas) (CONTEL, 2014, p.2)

Desse modo, embasada na necessidade de produção de informações fidedignas sobre o território nacional, as pesquisas sobre o País caminharam na perspectiva de elaboração e adoção de uma única divisão territorial que pudesse atender tanto as ações governamentais, por meio da divulgação de informações estatísticas, quanto ao ensino da ciência geográfica (CONTEL, 2014, p.2; IBGE, 2017 p.13).

Sobre o tema em discussão, Rocha e Oliveira (2011, p. 38) abalizam de forma sintética que: 
[...] as novas realidades nacionais, que se acentuaram na década de 30, ajudam a entender as preocupações do Governo Federal em estabelecer pela primeira vez no Brasil uma divisão regional oficial. Seria uma divisão regional que não estaria simplesmente a serviço de uma melhor gestão dos serviços públicos, como acentuava o discurso oficial, mas que estaria também a serviço da implantação de um projeto nacional unificado.

Isto posto, a necessidade de ações estatais voltadas mais especificadamente para o conhecimento e organização do território nacional põe em destaque na agenda política do governo em vigor, a urgência de uma redefinição do mapa político nacional, tanto no que diz respeito às suas fronteiras internas (de suas unidades político-administrativas), quanto das suas fronteiras externas (IBGE, 2017). Nesse ínterim, Contel (2014, p. 1) destaca que, ao longo do século XX, o IBGE estabeleceu três divisões regionais para o Brasil, sendo estas "oficializadas nos anos de 1942, 1970 e 1990 através de normas federais e do próprio IBGE".

Para Haesbaert (2000):

O Brasil, país de extensão e diversidade geográficas continentais, expressa o dilema da regionalização em múltiplas escalas. Aliás, não podemos esquecer que regionalizar é também uma questão de escala - durante muito tempo foi sobretudo uma questão escalar, definida estritamente no nível intermediário entre 0 nacional e 0 "local". Assim, apenas para ilustrar, o IBGE acabou legitimando três níveis de regionalização, dividindo o País em macro, meso e microrregiões.

É relevante ainda esclarecer que, antes da primeira divisão regional oficial do País, em 1942, várias as propostas tiveram significativa projeção em âmbito nacional. Apesar de não terem caráter oficial, muitas dessas propostas serviram de base para estudos posteriores. Entre estas, destacaram-se: i) o zoneamento de Hugo Hamann, que trata da fisionomia econômica brasileira; ii) o zoneamento de Josué de Castro, sobre os tipos regionais de alimentos; iii) o zoneamento geoeconômico do Conselho Técnico de Economia e Finanças - CTEF, do Ministério da Fazenda, e por fim; iv) as de Everardo Backheuser e Delgado de Carvalho, este último sendo responsável pela consolidação teórica dos estudos regionais ainda no início do Século XX e pela introdução do conceito de região natural. Todas estas pesquisas eram voltadas tanto para fins específicos de órgãos públicos e/ou privados, quanto para inspiração geopolítica, focadas na perspectiva de modernização, que era um dos principais objetivos do governo durante o chamado Estado Novo (IBGE, 2017, p.60).

Conforme mencionado anteriormente, da criação do IBGE a um intervalo de aproximadamente meio século foram elaboradas três propostas de divisão regional para o território brasileiro. Foram: as Zonas Fisiográficas de 1940 e suas revisões; as Microrregiões Homogêneas de 1968 e, por fim, as Mesorregiões e Microrregiões Geográficas de 1989 (IBGE, 2017).

O ano de 1941 marcou o estabelecimento do primeiro modelo de divisão regional oficial elaborado pelo IBGE para o Brasil. A metodologia usada nesta proposta de regionalização baseou-se na divisão de todo o território nacional em cinco Grandes Regiões [Norte, Nordeste, Leste, Sul e centro-Oeste], identificadas por apresentarem características homogêneas com relação aos aspectos físicos e destas, se (sub)dividiria sucessivamente unidades menores, ou seja, as Zonas 
Fisiográficas que, por sua vez, levavam em consideração também os aspectos socioeconômicos (IBGE, 2017).

É imperativo esclarecer que esse modelo foi conceitualmente pautado nas características do meio físico, visto à época, como elemento diferenciador do quadro regional brasileiro. Nesse período, predominava a noção de região natural para a compreensão do espaço geográfico. Em outras palavras, Contel $(2014$, p. 4) destaca que "as regiões naturais possuem um caráter mais estável ao longo do tempo [...], e esta estabilidade seria condição sine qua non para a coleta e comparação dos dados estatísticos ao longo do tempo".

Assim, o primeiro modelo oficial de divisão regional do Brasil, apoiou-se na concepção determinista da Geografia Clássica que, segundo seus pressupostos teóricos, uma divisão regional deveria ter caráter duradouro, portanto, deveria ser elaborada segundo a análise das características físicas do território, por serem considerados mais estáveis (IBGE, 2017).

Considerando essas premissas, em 1942 o Conselho Nacional de Geografia avaliou que "a divisão das Unidades da Federação brasileiras em Zonas Fisiográficas comportava revisões e atualizações que as tornassem mais próximas do que eram consideradas as características geográficas dominantes" (IBGE, 2017, p.61) (Figura 1).

FIGURA 1: Divisão Regional do Brasil em Zonas Fisiográficas de 1942.

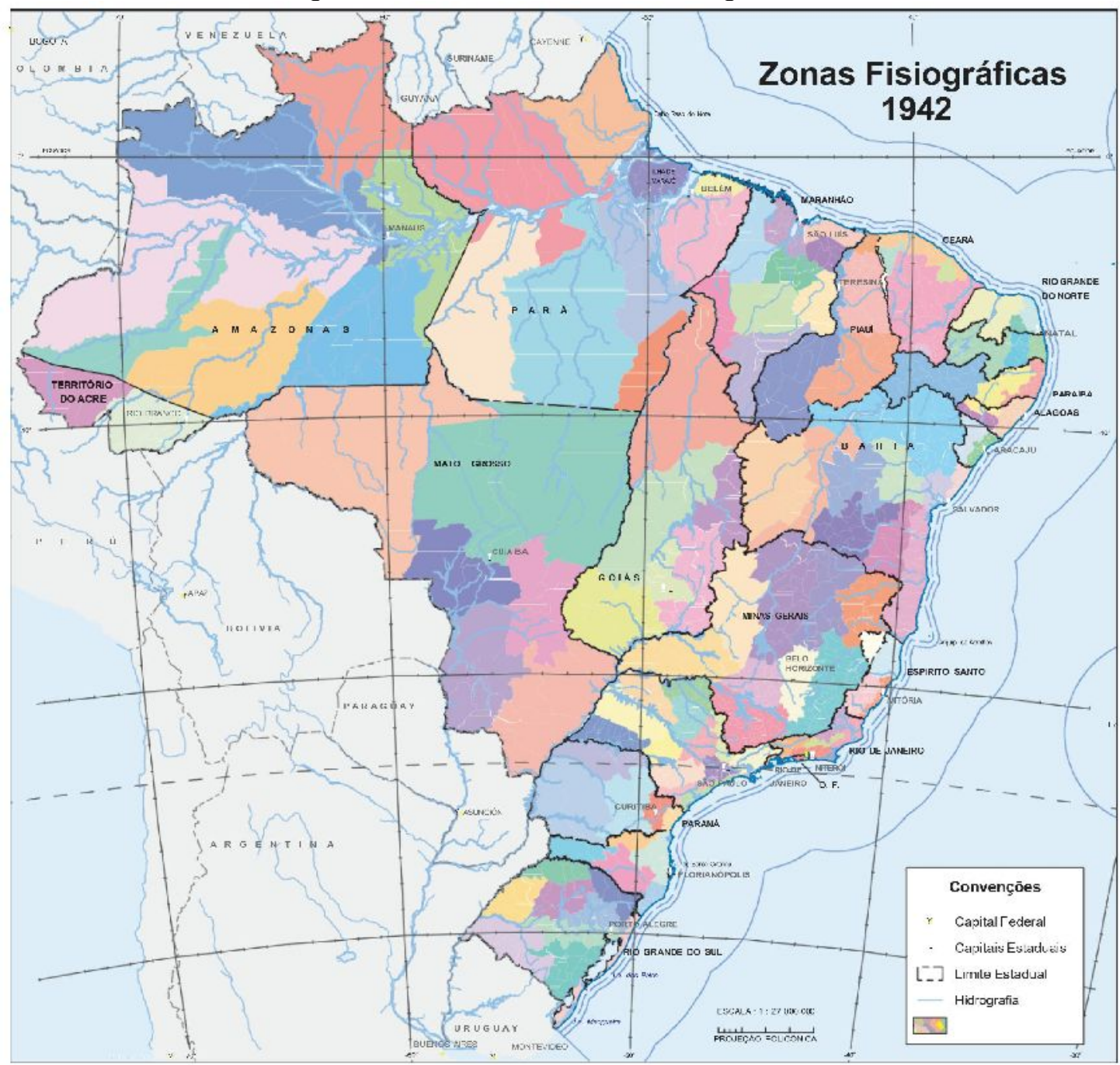

Fonte: IBGE (2017). 
Após algumas revisões e com a inserção dos fatores econômicos e sociais como elementos que também influenciam no processo de divisão de um território, o modelo de 1942 foi oficialmente substituído pelas Zonas Fisiográficas, de 1960 (IBGE, 2017) (Figura 2).

FIGURA 2: Divisão Regional do Brasil em Zonas Fisiográficas de 1960.

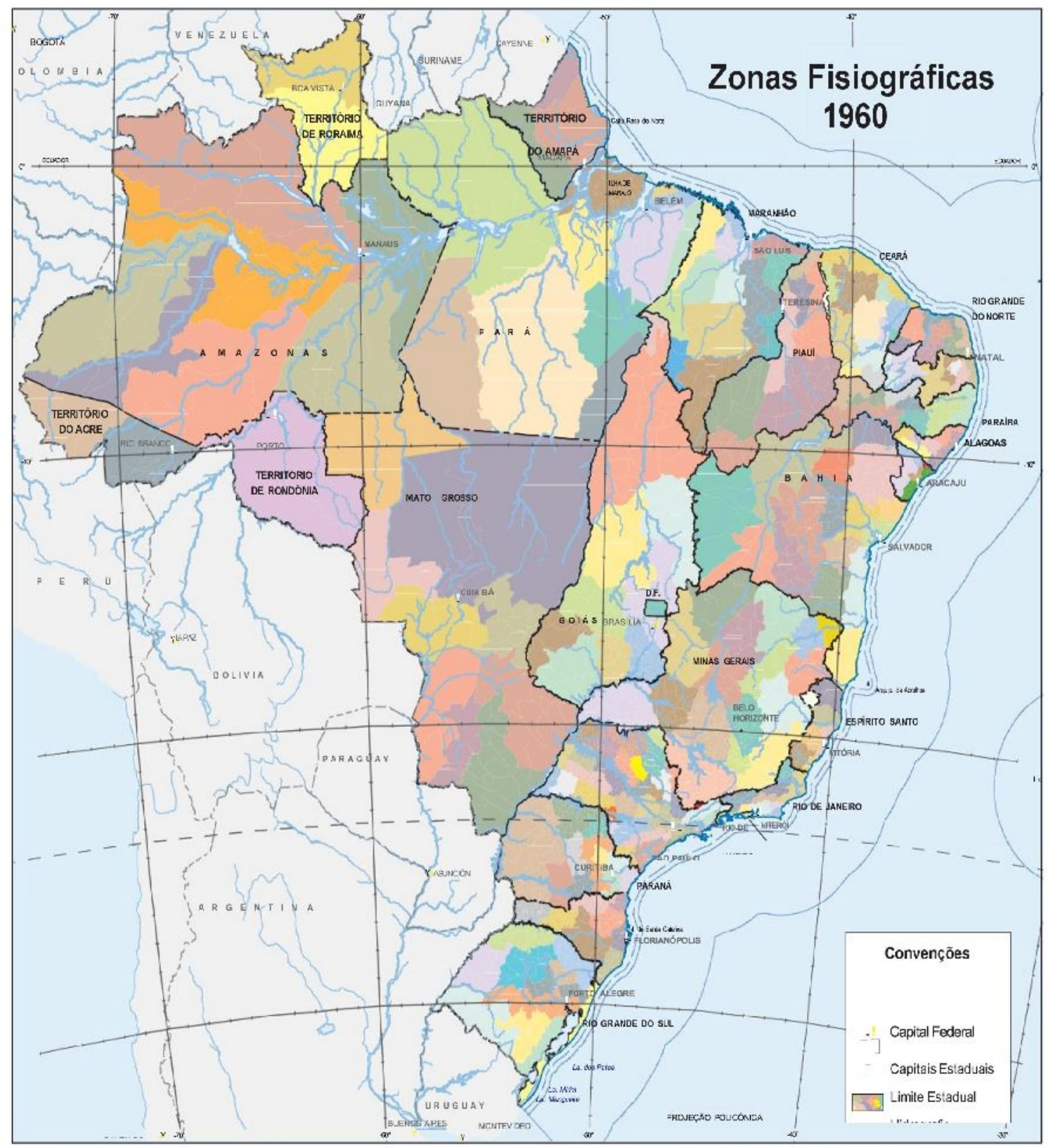

Fonte: IBGE (2017).

Baseado no exposto avalia-se que, datada da primeira metade da década de 1940, a divisão regional oficial brasileira em Zonas Fisiográficas é implementada durante um contexto político-institucional, no qual se deu a abertura do processo de restabelecimento do sistema democrático no País, iniciado no final do Estado Novo (1937-1945) e caracterizado ainda, entre outros fatores, pela forte centralização do poder (IBGE, 2017).

Nessa época, o Brasil, País com dimensão territorial continental, precariamente articulado socioeconomicamente, população predominantemente 
rural e com pouco e/ou insuficiente conhecimento sobre a população e território, exigia urgentemente uma tomada de medidas no que se referia a elaboração de estratégias voltadas à integração e a manutenção da integridade nacional. O modelo de regionalização em Zonas Fisiográficas surgiu, portanto, da necessidade de um aprofundamento do conhecimento sobre a população e o território Nacional (IBGE, 2017).

É relevante ressaltar que, durante o período de mais de duas décadas de regência da divisão regional em Zonas Fisiográficas observou-se exemplos claros e significativos de ações de ordenamento territorial posto em prática pelo Estado através de seus órgãos institucionais. É fruto dessa época as primeiras alterações do mapa político nacional, a abertura para os processos de interiorização, industrialização, urbanização e integração do território brasileiro, entre outros (IBGE, 2017).

Passadas quase três décadas desde a formulação da primeira divisão regional do Brasil surgiu a necessidade de um novo modelo de regionalização para o País, haja vista a significativa mudança em sua configuração territorial, sobretudo, após a Segunda Guerra Mundial. No final da década de 1960 a centralização do poder ainda era bem expressiva, todavia destacava-se no cenário nacional um processo de industrialização, urbanização e crescimento demográfico em intensa ebulição. Com efeito, tanto o modelo de divisão regional da década de 1940 quanto o arcabouço teórico metodológico tornaram-se inadequados à nova realidade brasileira. Mediante toda essa conjuntura, o IBGE elaborou no ano de 1968 uma nova divisão regional para o Brasil, denominada de Microrregiões Homogêneas (IBGE, 2017; CONTEL, 2014, p.5) (Figura 3).

FIGURA 3: Divisão Regional do Brasil em Microrregiões Homogêneas de 1968.

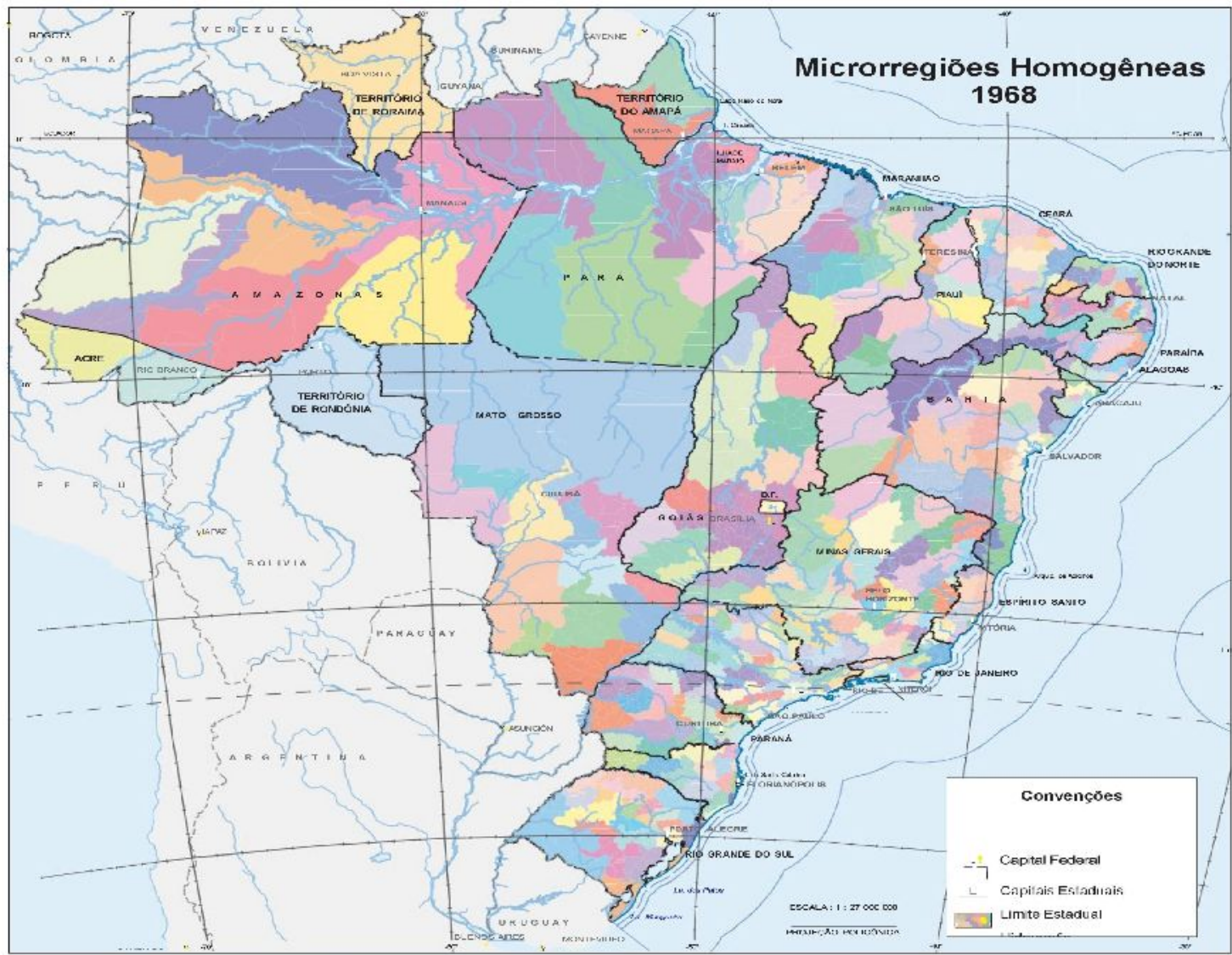

Fonte: IBGE (2017). 
A regionalização em Microrregiões Homogêneas de 1968 alterou o quadro das chamadas Macrorregiões Naturais do País. Além da redefinição das cinco Grandes Regiões (atualmente, Região Norte, Nordeste, Sul, Sudeste e CentroOeste), essa divisão regional buscou demarcar os espaços homogêneos e polarizados do território brasileiro. A implementação das chamadas Microrregiões Homogêneas ocorreu em substituição às antigas Zonas Fisiográficas, de 1942. Alicerçada nos ideais da Geografia Teorética-Quantitativa ou Nova Geografia, essa regionalização teve como eixo norteador a dimensão espacial do desenvolvimento econômico do País, reforçado pelo próprio conceito de região, bem como, pelo planejamento, desenvolvimento e desigualdades regionais (IBGE, 2017, p. 66).

Sobre o molde de regionalização em Microrregiões Homogêneas, Contel (2014, p.8) pondera que:

Elas foram de extrema importância, pois serviram para
agrupamentos de informações sobre a população, a produção, a
sociedade com maior correspondência às bases física, demográfica
e econômica de cada parcela do espaço nacional [...]. Ao total foram
definidas 361 "microrregiões homogêneas" para o território brasileiro,
sendo 28 delas na Região Norte, 128 no Nordeste, 111 no Sudeste,
64 no Sul e 30 no Centro-Oeste.

Como já era previsto, a Divisão Regional do Brasil em tela passou por uma nova revisão e no final da década de 1970, as Microrregiões ganharam um nível intermediário de aglomerados espaciais, as chamadas Mesorregiões Homogêneas (Figura 4). Estas foram definidas, entre outros fatores, pelas atividades econômicas e indicadores de desenvolvimento urbano e rural (IBGE, 2017).

FIGURA 4: Divisão Regional do Brasil em Mesorregiões Homogêneas de 1976.

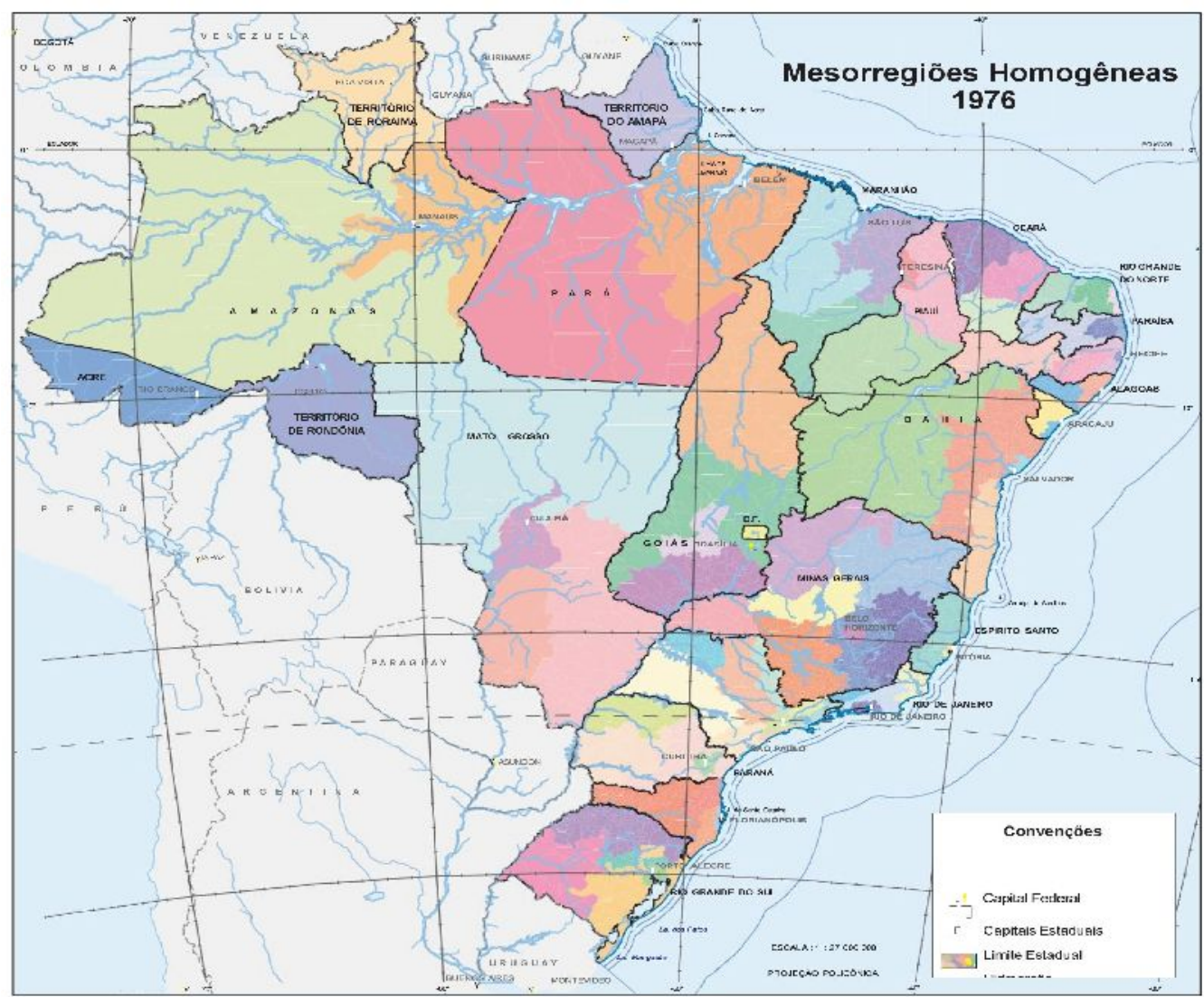

Fonte: IBGE (2017). 
Novamente, as alterações nos cenários político e socioeconômicos do País, tornaram o modelo de divisão regional proposto no final da década de 1960 (e revisado uma década depois) insatisfatório a presente realidade nacional. Os anos de 1970 assinalam o período em que o processo de urbanização do País atinge índices muito consistentes e a população brasileira passa a ser predominantemente urbana, mudando consideravelmente a estrutura da rede urbana nacional. Nesse cenário, o percentual da população urbana corresponde a $56,80 \%$, em detrimento aos 43,20\% da população residente na zona rural (SANTOS, 2018 [1993], p.32). Dada essa realidade, Contel (2014, p.9) reforça que para se chegar a uma nova regionalização do País, o estudo das redes urbanas passa a ser uma condição sine qua non.

Diante o exposto, surge o último modelo de divisão regional do Brasil proposto pelo IBGE no século XX. Portanto, entrou em vigor no final da década de 1980, a regionalização do território nacional em Mesorregiões e Microrregiões Geográficas. A principal diferença entre esse novo modelo e os anteriores está no fato dessa nova regionalização apoiar-se na totalidade nacional, tendo as Unidades da Federação como universo de análise e não mais a agregação de áreas homogeneizadas, como ocorria nas divisões anteriores (IBGE, 2017; CONTEL, 2014, p.10-11). Outrossim, é pertinente reforçar que, em conformidade com os apontamentos de Contel (2014, p.12):

A divisão regional proposta pelo IBGE no ano de 1990, ainda que tenha mantido em grande parte alguns dos "paradigmas" da divisão de 1970, aprimorou tanto a metodologia para a definição efetiva das micro e mesorregiões, quanto se preocupou em incorporar conceitos e categorias dinâmicas nestas definições (como os conceitos de "processo social", "relações de produção", "identidade regional", "elementos estruturadores do espaço" etc.) [...].

Isto posto, com base nessa nova divisão regional, entende-se que as Mesorregiões Geográficas (Figura 5) representam uma área individualizada das Unidades da Federação que apresentam uma forma de organização do espaço geográfico definidas através do processo social (fator determinante), do quadro natural (fator condicionante) e da rede de comunicações e lugares (elemento de articulação espacial). Nesse sentido, "essas três dimensões possibilitam que o espaço delimitado como Mesorregião tenha uma identidade regional. Essa identidade é uma realidade construída ao longo do tempo pela sociedade que aí se formou" (IBGE, 2017, p.72). 
FIGURA 5: Divisão Regional do Brasil em Mesorregiões Geográficas de 1989.

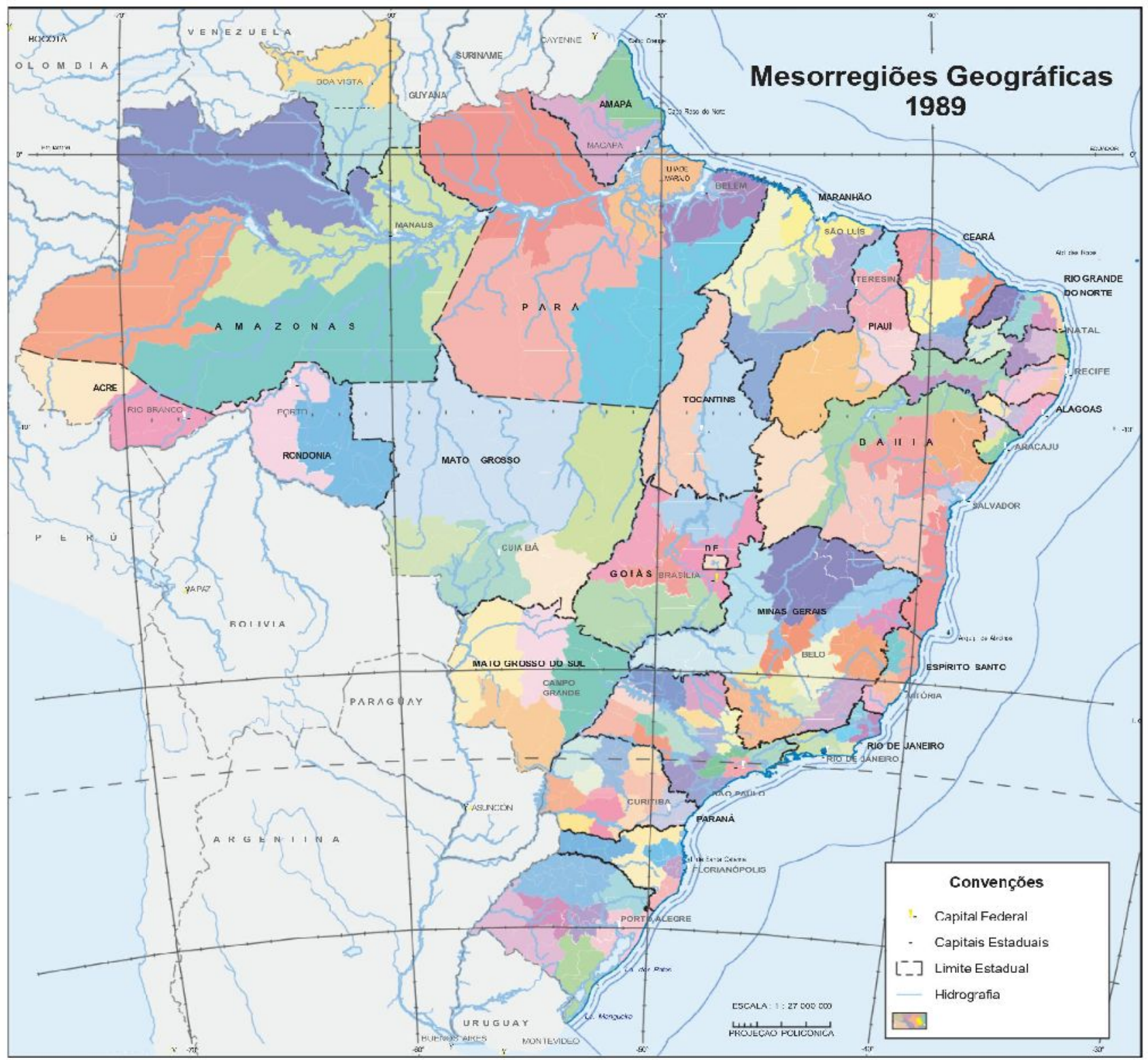

Fonte: IBGE (2017).

As Microrregiões Geográficas (Figura 6), por sua vez, consideradas como partes das Mesorregiões, foram definidas em virtude de apresentarem especificidades tanto em relação a organização do espaço, ou melhor, à estrutura da produção agropecuária, industrial, extrativa mineral e pesqueira, quanto as informações sobre o quadro natural e sobre relações sociais e econômicas (IBGE, 2017, p. 74). 
FIGURA 6: Divisão Regional do Brasil em Microrregiões Geográficas de 1989.

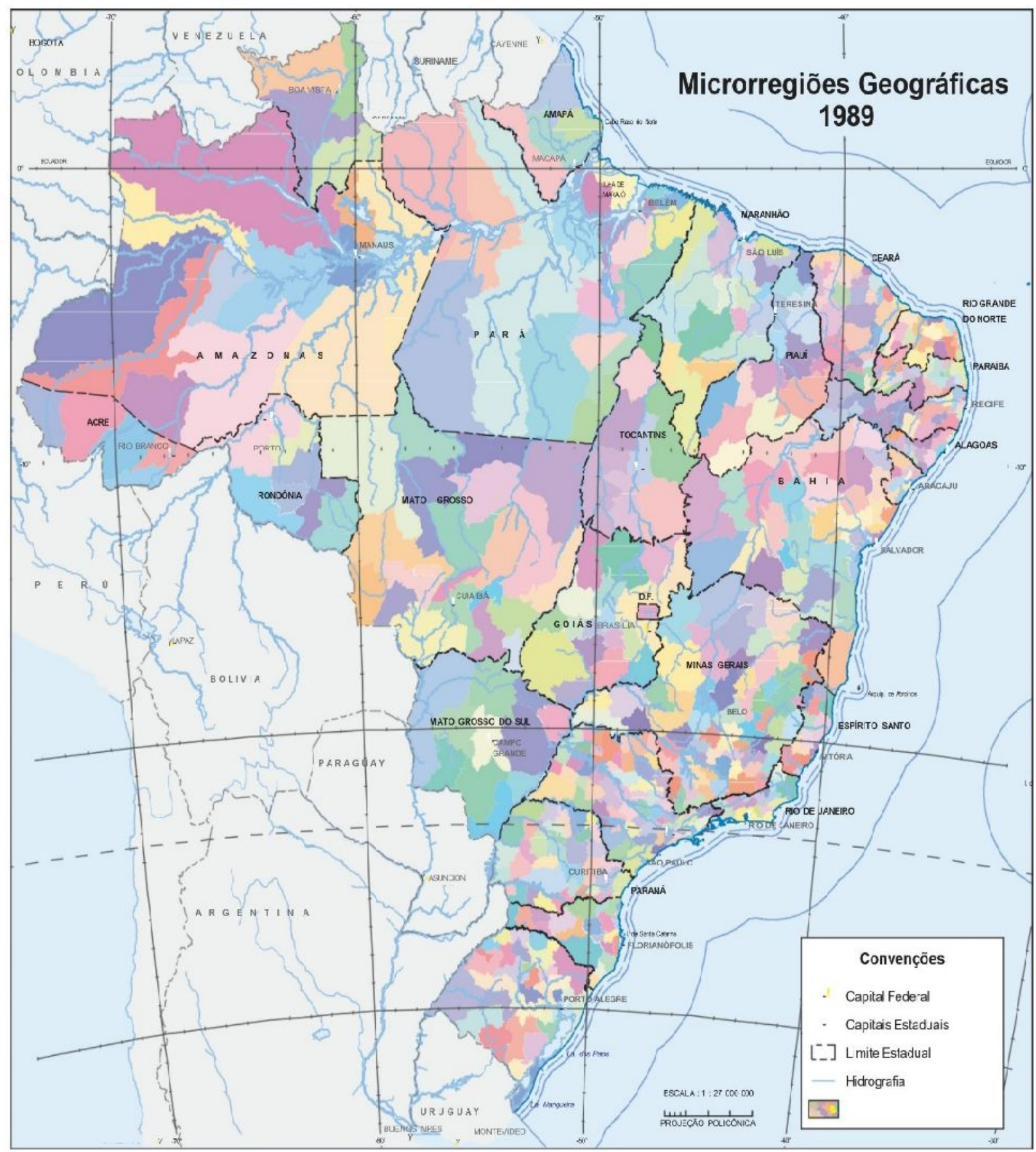

Fonte: IBGE (2017).

Em linhas gerais, é pertinente ainda reforçar o entendimento inerente ao alinhamento do contexto político-institucional do Brasil às distintas etapas de formulação das propostas de regionalização implementadas pelo IBGE, grosso modo, em conformidade com o IBGE (2017, p.17):

Entre a formulação da primeira proposta das Zonas Fisiográficas (década de 1940) e a das Microrregiões Homogêneas (1968), podese afirmar que, em termos do contexto político-institucional, enquanto a primeira divisão regional promovia o conhecimento mais acurado do território, em um País ainda dominantemente rural, a segunda 
divisão tinha como estímulo central o conhecimento das diferenças e desigualdades regionais com vistas à unificação do mercado, em um País que se urbanizava e se industrializava rapidamente (IBGE, 2017).

Fechando esse ciclo de divisões regionais implementadas pelo IBGE durante o século XX, cabe apontar algumas modificações na estrutura territorial e políticoadministrativa do Brasil. O novo mapa político do País contempla o acréscimo do Estado do Mato Grosso do Sul, na Região Centro-Oeste; a fusão do Estado da Guanabara ao Estado do Rio de Janeiro, na Região Sudeste; a adição do Estado do Tocantins à Região Norte e, por fim, a transformação dos territórios de Rondônia, Roraima e Amapá em Estados da Região Norte. Quanto à divisão Macrorregional, continua prevalecendo aquela estrutura estabelecida na década de 1970 (IBGE, 2017, p.74-75).

\section{O SÉCULO XXI E A URGÊNCIA DE UMA NOVA REGIONALIZAÇÃO PARA O BRASIL}

O cenário brasileiro apresenta-se, neste início de século, bastante modificado quando comparado àquele analisado no final dos anos de 1980. As consistentes transformações ocorridas nos setores econômicos, demográficos, políticos e ambientais do País, sobretudo, nas três últimas décadas, bem como, as lacunas evidenciadas pelo modelo de regionalização em Mesorregiões e Microrregiões Geográficas, no tocante a análise e planejamento do território nacional, imprimiram a urgência de uma nova proposta de regionalização (IBGE, 2017, p. 19). Concernente ao exposto, Limonad (2015, p. 54) destaca com primazia os principais elementos que fomentaram tais mudanças:

Três processos interligados desencadeados e em curso nas duas
últimas décadas (a revolução tecnológica informacional, genética e
energética; a formação de uma economia global com a
reestruturação dos processos econômicos em escala planetária ; a
emergência de novas formas de produção e gerenciamento, com a
constituição de redes de interações que vão do local ao global)
contribuíram para uma alteração substantiva nas relações sociais de
produção e na vida cotidiana em todas as partes do País e do
planeta.

Em outras palavras, o acentuado processo de fragmentação e articulação socioespacial do território brasileiro apresenta-se em relevo neste início de século, passando a constituir a base de estudos que culminará no novo recorte regional do País. Nesse processo, cabe destacar que diversos ensaios foram realizados no intuito de reorganizar a dinâmica e a estrutura da rede urbana do território brasileiro. Assim, dotado das mesmas estratégias que remontam a década de 1960, o IBGE lançou em 2007 a quarta edição do Projeto de Regiões de Influência das Cidades (REGIC), documento que definiu a hierarquia dos centros urbanos nacionais, bem como, delimitou as regiões de influência a estes associados ${ }^{1}$ (IBGE, 2017, p.19; 2020).

$1 \quad$ Em 2020 o projeto REGIC é novamente atualizado. A sua quinta edição (REGIC/2018) traz uma atualização do quadro da rede urbana brasileira, através de pesquisas sobre a hierarquia dos centros urbanos nacionais e da delimitação de suas respectivas áreas de influência. Este documento apresenta-se como um relevante instrumento de análise da dinâmica urbana nacional. Ao dar ENCICLOPÉDIA BIOSFERA, Centro Científico Conhecer - Jandaia-GO, v.18 n.38; p. 210 2021 
Sob essa ótica de divisão regional a partir da articulação das redes urbanas, o referido órgão apresentou no ano de 2013 um novo estudo sobre a divisão urbanoregional do território brasileiro, que integra e conclui o Projeto REGIC. Nesse estudo são identificadas três escalas regionais: as Regiões Ampliadas de Articulação Urbana (constituem as principais cidades que exercem influência em escala macrorregional); as Regiões Intermediárias de Articulação Urbana (regiões, cuja função dentro dessa rede, baseia-se no oferecimento e busca por bens e serviços de alta complexidade), e por fim, as Regiões Imediatas de Articulação Urbana (regiões que refletem a área vivida pela população e seu deslocamento mais cotidiano) (IBGE, 2017, p.22).

Além dos estudos acima mencionados, ensaios como a Divisão UrbanoRegional de 2007; a Gestão do Território de 2014; a Logística dos Transportes do Brasil, também de 2014 e os Arranjos Populacionais e Concentrações Urbanas do Brasil, de 2016, constituíram os principais documentos que embasaram a nova regionalização do território nacional, neste século (IBGE, 2017, p.22-23).

Conforme já mencionado, o alicerce desse novo modelo de regionalização encontra-se imerso na dinâmica geral da rede urbana nacional, moldada em face às transformações ocorridas nos cenários político e socioeconômico do País, sobretudo, a partir da última década do século passado. Nesse contexto, a relação entre as redes urbanas e o ordenamento do território é habilmente explicada por Diniz (2017, p.3). Conforme o autor:

As centralidades urbanas ordenam e comandam o território. Rede de cidades, através de suas hierarquias e a malha de infraestrutura, especialmente do sistema de transportes, determina, em última escala, o ordenamento do território e tem forte articulação com a distribuição demográfica e econômica dentro do mesmo.

Embasado nas discussões acima dispostas, compreende-se que esse novo arranjo do quadro urbano brasileiro trouxe à tona a necessidade de reconfiguração da antiga divisão regional do País em Microrregiões e Mesorregiões Geográficas, de 1989. Assim, no ano de 2017, o IBGE definiu o recorte das Regiões Geográficas Imediatas e Intermediárias como nova categoria de análise regional (IBGE, 2017, p. 19)

Conforme assinala o IBGE (2017, p.9), a principal diferença entre esses dois modelos de divisão regional está na periodicidade de revisão da atual proposta. Em alguns casos, ainda prevalece o uso do recorte regional em Microrregiões e Mesorregiões, pois, ao se manterem inalterados, os resultados desse modelo "facilitaram o uso em uma variedade de aplicações para as quais esta característica é importante e que poderão ser mantidas, a critério do usuário".

A metodologia utilizada para a elaboração desse modelo de divisão regional do território brasileiro teve como base de análise a identificação de cidades-polo e os municípios a estas vinculadas. Para tanto, definiu-se como postulado teórico, as concepções de território-rede e território-zona, amplamente analisado por Haesbaert (2005). Para o autor:

visibilidade às centralidades e à dinâmica dos fluxos que as conectam, endossa as decisões locacionais e aplicações práticas, ligadas tanto ao planejamento estatal quanto da sociedade como um todo (IBGE, 2020). 
Graças à fluidez crescente nos/dos espaços e à dominância do elemento rede na constituição de territórios, conectando suas parcelas descontínuas, temos o fortalecimento não mais de um mosaico padrão de unidades territoriais em área, vistas muitas vezes de maneira exclusiva entre si e as quais se denominam territórioszona, mas uma miríade de "territórios-rede", marcada pela descontinuidade e pela fragmentação (articulada) que possibilita a passagem constante de um território a outro [...] (HAESBAERT, 2005, p.19).

Em conformidade com o autor acima, percebe-se que a análise do território, sob o viés da apropriação do espaço pela sociedade, não pode se restringir somente a fixidez e a estabilidade. Assim, os conceitos de território-rede e território-zona são compreendidos a partir da interação dos fluxos e dos fixos num espaço contínuo e homogêneo. É essa inter-relação que constitui a base conceitual de análise da rede urbana nacional.

Desse modo, de acordo com o novo recorte regional do território brasileiro entende-se por Região Geográfica Imediata, aquelas regiões estruturadas a partir de centros urbanos próximos, cujo objetivo principal é prover as necessidades imediatas das populações, tais como: compras de bens de consumo duráveis e não duráveis; busca de trabalho; procura por serviços de saúde e educação; e prestação de serviços públicos, como postos de atendimento do Instituto Nacional do Seguro Social - INSS, do Ministério do Trabalho e de serviços judiciários, entre outros (IBGE, 2017, p.20).

As Regiões Geográficas Intermediárias, por sua vez, têm a função de organizar o território, articulando as Regiões Geográficas Imediatas por meio de um polo de hierarquia superior diferenciado a partir dos fluxos de gestão privado e público e da existência de funções urbanas de maior complexidade (IBGE, 2017, p.20).

Finalmente, é relevante esclarecer que, nesse atual recorte do território nacional percebe-se uma propositiva consonância das teorias e métodos aplicados à diversidade e a complexidade das diferenças regionais do País. Por fim, à guisa das discussões apresentadas neste artigo conjectura-se que, não obstante as heterogeneidades que abrangem o território brasileiro, as divisões regionais implementadas pelo IBGE desde o século XX, apresentam-se como um dos principais instrumentos de fomento ao planejamento e ordenamento territorial do Brasil.

\section{CONSIDERAÇÕES FINAIS}

As análises desenvolvidas nesse artigo tiveram como pano de fundo o ordenamento territorial do Brasil contextualizado sob a perspectiva das diferentes regionalizações implementadas pelo IBGE ao longo dos séculos XX e XXI. Conforme analisado, as diferentes propostas de regionalização do território brasileiro foram embasadas por distintas tipologias metodológicas e conceituais, assim como, pela dinâmica político/institucional responsável pela promoção de diversas mudanças no cenário socioeconômico do País ao longo de todo esse percurso.

De forma ampla, pode-se afirmar que todas as regionalizações implementadas pelo o IBGE, além das funções didáticas e estatísticas, sempre estiveram direcionadas ao conhecimento do território nacional, buscando 0 alinhamento das relações entre os diferentes recortes regionais às políticas públicas 
ou programas de fomento ao ordenamento e, consequentemente, desenvolvimento do País.

Por fim, tomando-se por base a análise contextualizada das propostas de divisão regional do Brasil elaboradas pelo IBGE ao longo dos dois últimos séculos, conjectura-se que toda a dinâmica que envolveu esse processo foi marcada por intensa complexidade. De fato, regionalizar de forma coerente e consistente um país marcado por significativa heterogeneidade não é tarefa fácil. Contudo, é pertinente ressaltar que todos os modelos propostos foram formulados de acordo com a realidade vigente e que seus objetivos sempre estiveram direcionados ao conhecimento, ordenamento e gestão do território nacional.

\section{REFERÊNCIAS}

ANDRADE, M. C. de. Formação Territorial e Econômica do Brasil. Recife: Editora Massangana, 2003, 248p.

A questão do território no Brasil. $2^{\text {a }}$ ed. São Paulo: Hucitec, 2004.

ARAÚJO, G. C.C. de. Regionalizar para integrar. In: Boletim Paulista de Geografia. v. 97, 2017, p.122-145. Distrito Federal. Disponível em: https://www.academia.edu/37559452/Regionalizar_para_Integrar.pdf. Acesso em: dezembro de 2021.

CARVALHO, C.; ALVES, L.; SOUSA JUNIOR, A. Experiências de Ordenamento Territorial Urbano na América Latina: o contexto do Brasil. In: Revista de Geografia e Ordenamento do Território - GOT, n. 18. Dezembro de 2019. Disponível em: https://www.proquest.com/openview/eceb70192da7784d5e1e77fc66b7a598/1 ?pqorigsite $=$ gscholar $\& \mathrm{cbl}=3882644$. Acesso em: Outubro de 2021.

CONTEL, F. B. As divisões regionais do IBGE no século XX (1942, 1970 e 1990). In: Terra Brasilis (Nova Série), 3/2014. 10-21p. Niterói/RJ. Disponível em: https://journals.openedition.org/terrabrasilis/990. Acesso em: dezembro de 2021.

DASÍ, J. F. Gobernanza territorial para el desarrollo sostenible: Estado de la cuestión y agenda. In: Boletín de la A.G.E. n. 46 - 2008, pg. 11-32. Disponível em: http://www.dhl.hegoa.ehu.es/ficheros/0000/0563/Gobernanza.pdf. Acessado em 15/08/2017.

DINIZ, C. C. Dinâmica regional e ordenamento do território brasileiro: desafios e oportunidades. In: Revista Catarinense de Economia, v. 1, n. 1. Florianópolis/SC, 2017. Disponível em: https://www.apec.pro.br/rce/index.php/rce/article/view/2/1. Acesso em: Novembro de 2021.

FURTADO, C. Formação econômica do Brasil. 34ำ edição. São Paulo: Companhia das Letras, 2007 [1959].

FREITAS-FIRKOWSKI, O. L. C. de. A contribuição do IBGE para as leituras do território nacional na perspectiva da metropolização do espaço. In: Revista Brasileira de Geografia. v. 64, n. 1, p. 93-108, jan./jun. 2019. Rio de Janeiro/RJ. Disponível em: https://rbg.ibge.gov.br/index.php/rbg/article/view/2187. Acesso em: novembro de 2021. 
HAESBAERT, R. Desterritorialização, Multiterritorialidade e Regionalização. In: Ministério da Integração Nacional (MI). Para pensar uma Política Nacional de Ordenamento Territorial: anais da Oficina sobre a Política Nacional de Ordenamento Territorial. Brasília: MI, 2005. p.15-29.

Regionalizações brasileiras: antigos legados e novos desafios. In: Confins (Revista Franco-brasileira de Geografia). 44/2020. Disponível em: https://doi.org/10.4000/confins.26401. Acesso em: dezembro de 2021.

IBGE. Divisão regional do Brasil em regiões geográficas imediatas e regiões geográficas intermediárias: 2017. IBGE: Coordenação de Geografia. Rio de Janeiro: IBGE, 2017. 82p.

Regiões de Influência das cidades 2018. Rio de Janeiro: IBGE, 2020. 196p. Disponível em: https://www.ibge.gov.br/geociencias/cartas-e-mapas/redesgeograficas/15798-regioes-de-influencia-das-cidades.html?=\&t=acesso-ao-produto. Acesso em: fev. 2020.

LIMONAD, E. Brasil século XXI, regionalizar para que? Para quem? In: LIMONAD, E.; HAESBAERT, R.; MOREIRA, R. (Orgs.). Brasil, século XXI - por uma nova regionalização? Agentes, processos, escalas. Rio de Janeiro: Letra Capital Editora, 2015. 214p.

MOREIRA, R. Pensar e ser em Geografia: ensaios da história, epistemologia e ontologia do espaço geográfico. 2. ed., $2^{\underline{a}}$ reimpressão. São Paulo: Contexto, 2019. 188p.

OLIVEIRA, N. M. de. Território: contributo sobre distintos olhares. In: Revista Tocantinense de Geografia Araguaína. v. 09, n. 17, Jan-Abr (2020). Palmas/TO, 2020.

Disponível em: https://sistemas.uft.edu.br/periodicos/index.php/geografia/article/view/8032/16567.

Acesso em: novembro de 2021.

PORTUGAL, R.; SILVA, S. A. da. História das políticas regionais no Brasil. Brasília: IPEA, 2020. 130p.

PUJADAS, R.; FONT, J. Ordenación y Planificación Territorial. Madrid: España: Sintesis, 1998.

ROCHA, A. P. B.; OLIVEIRA, M. S. da. Geografia Regional do Brasil. $2^{a}$ ed. Natal/RN: Editora da UFRN, 2011. 312p.

SANTOS, M. A urbanização brasileira. 5a ed. 4ํㅜ reimpressão. São Paulo: EDUSP, 2018 [1993].

SANTOS, M.; SILVEIRA, M. L. O Brasil: território e sociedade no início do século XXI. 18 ${ }^{\text {a }}$ ed. Rio de Janeiro: Record, 2014.

SILVA, S. A. da. Projeto nacional e políticas territoriais no Brasil. In: COSTA, W. M. da; VASCONCELOS, D.B. (Orgs.). Geografia e geopolítica da América do Sul: integrações e conflitos. São Paulo: Humanitas, 2018. 
SPOSITO, E. S.; SAQUET, M. A. O conceito de território no Brasil: entre o urbano e o rural. In: Caderno Prudentino de Geografia, n.38, v.2, p.84-112, ago./dez. 2016. Presidente Prudente/SP. Disponível https://revista.fct.unesp.br/index.php/cpg/article/view/5502/4101. em: novembro de 2021. 